\title{
Design Performance and Frequency Response Analysis of SAW-Based Sensor for Dichloromethane Gas Sensing Amidst the COVID-19
}

\author{
Mukesh Kumar $^{1} \cdot$ Deepak Bhadu ${ }^{2}$
}

Received: 26 May 2020 / Revised: 2 October 2020 / Accepted: 9 October 2020 / Published online: 26 October 2020

(c) Krishtel eMaging Solutions Private Limited 2020

\begin{abstract}
Background To avoid the risk of increase in the rate of human infection is a big challenge for healthcare staffs during the treatment of patients affected from corona virus disease-2019 (COVID-19). This work is intended to save COVID-19-infected patients from conveyed hazardous volatile gases (VOCs) by the gas stream. The VOCs are generally generated from the pathways of medical respiratory devices.

Method Here, we present a surface acoustic wave-based sensor device for sensing dichloromethane (DCM) gas that can be connected with a gas pathway system used in medical devices. Dichloromethane is a volatile organic compound. Single- (polyisobutylene, $\mathrm{PIB}$ ) and multi- (polyisobutylene/silicon nitride, $\mathrm{PIB} / \mathrm{Si}_{3} \mathrm{~N}_{4}$ ) surface acoustic wave-based sensors are designed on $\mathrm{LiNbO}_{3}$ piezoelectric substrate. The designed models patterned with interdigitated transducer (IDT) aluminum (Al) electrodes are used to analyze gas sensing behavior for dichloromethane $\left(\mathrm{CH}_{2} \mathrm{Cl}_{2}, \mathrm{DCM}\right)$ gas.

Results The studies for DCM gas sensing are carried out for single- and multi-layer models using COMSOL Multi-physics software. The resonant frequency and displacement are also observed for $100 \mathrm{ppm}$ gas concentration of DCM at room temperature. It has been found that multi-layer designed model shows higher sensitivity as compared to single layer (PIB/ $\mathrm{LiNbO}_{3}$ ) model on exposing DCM gas.

Conclusion The estimation of various parameters observed by the proposed module is also explained. It is observed that the sensitivity of sensor for detection of VOCs (generated in gas pathways in medical devices) is best suited in the present crisis of COVID-19 pandemic.
\end{abstract}

Keywords SAW sensor COVID-19 $\cdot$ Medical gas pathways $\cdot$ Polyisobutylene $\cdot$ Silicon nitride $\cdot$ Piezoelectric substrate . COMSOL $\cdot$ Dichloromethane gas sensing

\section{Introduction}

The World Health Organization (WHO) has declared COVID-19 (corona virus disease-2019) as a highly infectious disease and world health emergency. The recovery and safety treatments of corona virus-infected patients are much essential to avoid further spreading of this disease. Several volatile organic compounds (VOCs) arise from the medical respiratory device itself during the supply of breathing gases to the patient [1]. Such types of compounds can affect

Mukesh Kumar

mail2mukeshsharma@gmail.com

1 Department of Electronics and Communication, National Institute of Technology (NIT), Kurukshetra, India

2 School of VLSI Design and Embedded System, National Institute of Technology (NIT), Kurukshetra, India the nervous system of the COVID-19-infected patient. To eliminate this problem, a VOCs' detection sensor based on surface acoustic wave is proposed and designed.

Smart sensors are widely used in control system, biomedical applications, industry, etc. MEMS technology provides a unique way to sense, process, and actuation of specific signal from several signals at microscopic level [2-4]. Surface acoustic wave (SAW) sensors are widely used for making several products containing resonators, actuators, detection of warfare agent, and gas sensors [5]. The main advantages of using MEMS Technology are in terms of scale and advanced technology [6]. The size of manufacturing device is shrinking from millimeters to micrometers which enables the researchers to make small size sensors nowadays.

SAW-based sensors can be realized from semiconductor process technology which is reconcilable with CMOS technology [7]. The mechanical waves propagate through 
the surface of piezoelectric material and are able to detect any changes on the surface [8]. The interaction of volatile compounds with the surface of the SAW-based sensor alters the electrons flow in the device and results in change of the sensitivity. Dichloromethane (DCM) is an organic solvent which is used in several industrial process applications. DCM bio-transformation can lead to the formation of carbon monoxide $(\mathrm{CO})$ gas, which is mixed with blood and reduces the amount of hemoglobin in blood cells [9]. The displacement and resonance frequency characteristics of piezoelectric SAW-based sensors are measured on changing of mass of the sensing layer during the interaction of gas molecules. SAW-based sensors are generally preferred over other sensors due to their high accuracy, small size, high sensitivity, low hysteresis, low power consumption, robust structure, and portability [10]. The changes in the characteristic of sensors are results from variation in pressure, temperature, humidity, and quality arbitrary gas concentration [11-13].
Piezoelectric materials are used to generate the acoustic waves [14]. The speed of surface acoustic waves depends on the type of material used. The piezoelectric materials such as $\mathrm{LiNbO}_{3}, \mathrm{LiTaO}_{3}$, and quartz are widely used in SAW gas sensors [15-17].

In the present work, two models of SAW-based sensors are designed and simulated for DCM gas concentration. The results indicate that the designed Multi-layer $\left(\mathrm{PIB} / \mathrm{Si}_{3} \mathrm{~N}_{4} /\right.$ $\mathrm{LiNbO}_{3}$ ) SAW sensor is more sensitive as compared to single-layer $\mathrm{PIB} / \mathrm{LiNbO}_{3} \mathrm{SAW}$ sensor. The change in temperature, pressure, and spacing layer thickness causes a significant change in the sensitivity of designed SAW sensors.

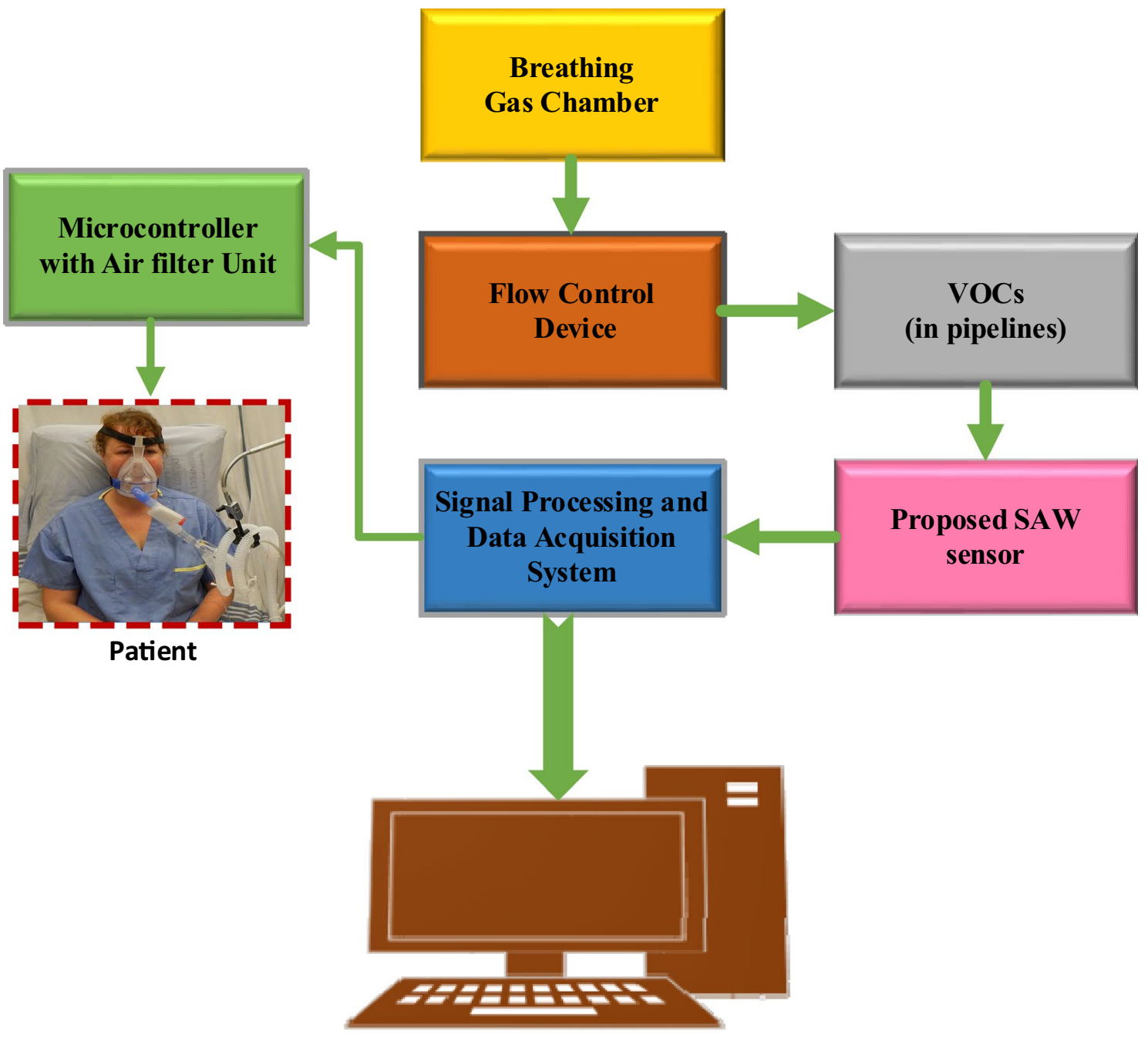

Fig. 1 Block scheme of proposed module 


\section{Design Parameter}

The monitoring of VOCs present in gas pathways to the patient is carried out by SAW-based sensor. The designed sensor is interfaced with a signal processing and data acquisition system, and also a microcontroller with air filter unit as shown in block scheme (Fig. 1).

The design structure and parameters of the sensor are described below.

\section{Single-Layer Structure (PIB/LiNbO $\left.{ }_{3}\right)$}

A thin layer of PIB is used as a sensing layer on $\mathrm{LiNbO}_{3}$ substrate having dimensions of width and length of 4 and $12.5 \mu \mathrm{m}$, respectively. The dimensions of interdigitated transducer aluminum (Al) electrode on substrate are $1 \mu \mathrm{m}$ width and $0.2 \mu \mathrm{m}$ height. Thin layer of PIB having the values of width $4 \mu \mathrm{m}$ and thickness $0.5 \mu \mathrm{m}$ designed model is shown in Fig. 2a.

\section{Multi-Layer Structure ( $\left.\mathrm{PIB} / \mathrm{Si}_{3} \mathrm{~N}_{4} / \mathrm{LiNbO}_{3}\right)$}

Design model for multi-layer sensor has an additional sensing layer of $\mathrm{Si}_{3} \mathrm{~N}_{4}$ having thickness of $0.5 \mu \mathrm{m}$ and width of $4 \mu \mathrm{m}$. It is placed over a thin film of PIB with a thickness of $0.5 \mu \mathrm{m}$ and a width of $4 \mu \mathrm{m}$. The IDT-type electrodes having width of $1 \mu \mathrm{m}$ and height of $0.2 \mu \mathrm{m}$ lay inside the spacer present on $\mathrm{LiNbO}_{3}$ substrate as shown in designed model in Fig. 2b.

\section{Simulation Methodology}

The 2D structure model for single- and multi-layer gas sensor is designed and simulated using COMSOL multiphysics software. The 2D structure is described as a unit cell of a 3D surface acoustic wave sensor. The SAW-based sensor device consists of interdigitated transducer (IDT) electrodes. The IDTs' electrodes are made up of either aluminum or gold [18]. The IDT is a metal comb-shaped structure fabricated over the piezo-substrate using lithography fabrication process [12]. Each IDTs' electrode used in SAW sensor have a length of 100 times more than their width. A periodic electric field is produced when an RF signal is applied to the IDT electrode, thus allowing piezoelectric coupling to a traveling surface wave. The schematic (geometry) view of SAW sensor is shown in Fig. 3.

The resonant frequency of the sensing layer is calculated by Eq. (1) by applying an RF voltage signal at one end of the IDT electrode. The potential at other end of the electrode is zero which produces a stress due to piezoelectric effect and generates a mechanical wave on the surface of SAW gas sensor:

$f_{\mathrm{r}}=V_{\mathrm{s}} / W$,

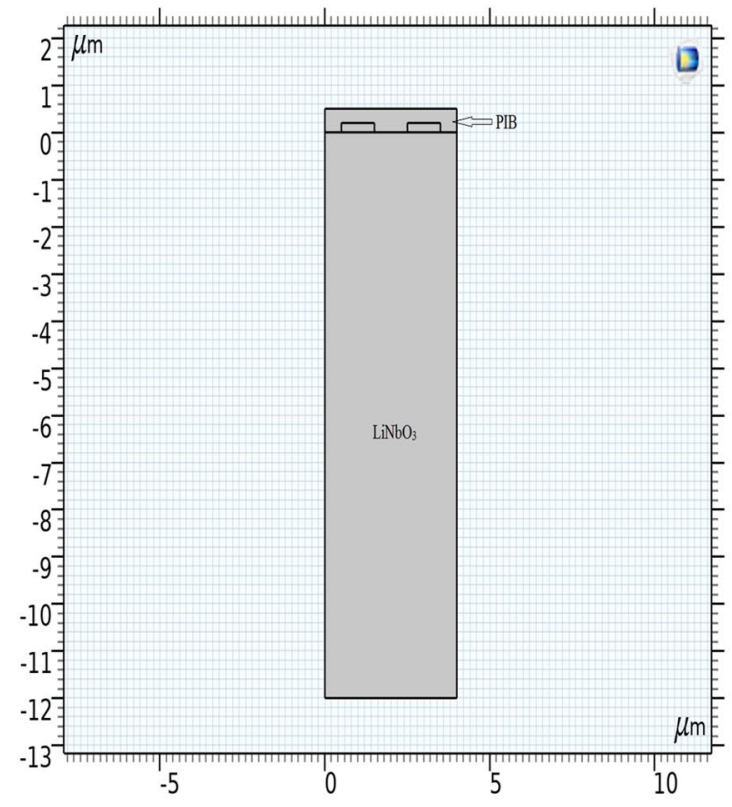

(a)

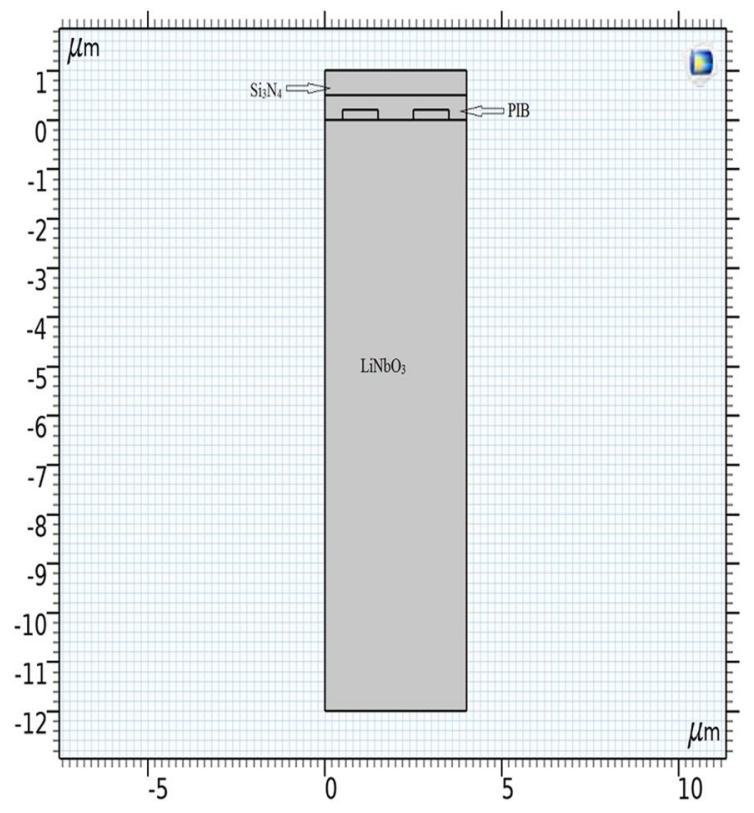

(b)

Fig. 2 Model of a single-layer, b multi-layer SAW-based gas sensor 
Fig. 3 Geometry of SAW sensor

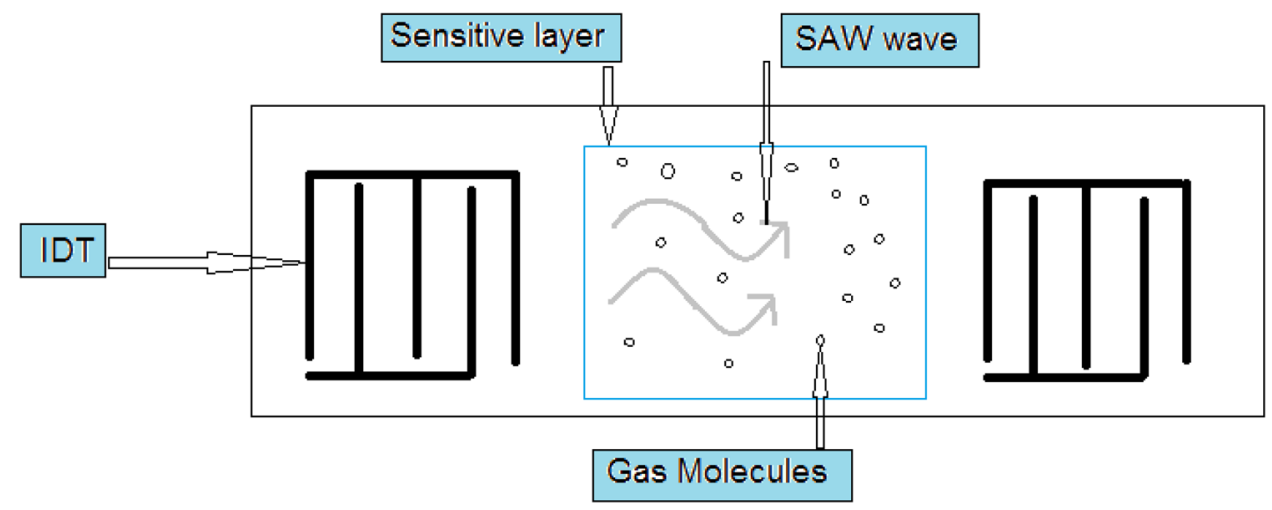

where $f_{\mathrm{r}}$ is resonant frequency, $V_{\mathrm{s}}$ is SAW velocity, and $W$ is width of unit cell. The SAW velocity is an important measurable parameter to determine the resonant frequency [19]. The density of sensing layer is found to change on exposure of DCM gas to PIB (polyisobutylene) film. Gas density ( $\rho$ ) in PIB film was evaluated by Eq. (2):

$\rho_{\mathrm{DCM}}=K M C$

$C=\left(c_{\mathrm{o}} \times 10^{-6} \times P\right) / R T$

$K=10^{1.4821}$,

where $P$ is pressure, $T$ is temperature, $R$ is gas constant, $c_{\mathrm{o}}$ is concentration in ppm, $M$ is its molar mass, $C$ is gas concentration in air, and $K=10^{1.4821}$ is the air/PIB partition coefficient for DCM.

\section{Results and Discussion}

\section{Frequency Shift and Displacement Measurement}

The values of resonant frequency of single-layered PIB/ $\mathrm{LiNbO}_{3}$ and for multi-layered $\mathrm{PIB} / \mathrm{Si}_{3} \mathrm{~N}_{4} / \mathrm{LiNbO}_{3}$ are calculated 0.855 and $0.829 \mathrm{GHz}$, respectively. Table 1 shows the measured frequency before and after exposing of $100 \mathrm{ppm}$ gas concentration of DCM at $25{ }^{\circ} \mathrm{C}$ temperature and at pressure of $1 \mathrm{~atm}$.
From Table 1, it is observed that multi-layered device model/structure $\mathrm{PIB} / \mathrm{Si}_{3} \mathrm{~N}_{4} / \mathrm{LiNbO}_{3}$ has been found to be more sensitive for DCM gas and high displacement than single-layer structure PIB/LiNbO 3 . From Fig. 4a, it is also determined that the value of displacement has been improved significantly and exhibits more shift in frequency in response to DCM gas.

Figure $4 \mathrm{~b}$ depicts that $\mathrm{Si}_{3} \mathrm{~N}_{4}$ act as an additional layer which improve sensitivity and stability. The dynamic performance of simulated multi-layer model helps in propagating the acoustic waves on surface only. It also protects the IDT electrode and substrate.

Polyisobutylene (PIB) is a polymer thin film having high affinity towards VOCs (DCM in this case). The mass of the PIB film is found to be increased as PIB selectively adsorbs $\mathrm{CH}_{2} \mathrm{Cl}_{2}$ (dichloromethane) from air [20-22]. This causes a shift in resonance which slightly lowers the resonance frequency for the same SAW mode. The sensing layer of silicon nitride $\left(\mathrm{Si}_{3} \mathrm{~N}_{4}\right)$ is used for electrical isolation between the interdigitated transducer aluminum (Al) electrodes and $\mathrm{LiNbO}_{3}$ piezoelectric substrate. The change in the acoustic wave velocity is caused by a mass increase due to the absorption of $\mathrm{CH}_{2} \mathrm{Cl}_{2}$ gas molecules on the structure surface.

\section{Electric Potential Measurement}

Figure $5 \mathrm{a}, \mathrm{b}$ shows the potential distribution for $\mathrm{PIB} / \mathrm{LiNbO}_{3}$ and $\mathrm{PIB} / \mathrm{Si}_{3} \mathrm{~N}_{4} / \mathrm{LiNbO}_{3}$ on exposing DCM gas. From Fig. 5b, it is observed that the generated voltage is also higher as compared to single layer. The potential distribution is also symmetric with respect to electrode.

Table 1 Frequency shift and displacement on exposure of DCM gas

\begin{tabular}{lllc}
\hline Device structure & $\begin{array}{l}\text { Resonant frequency (before exposure } \\
\text { to gas }=P)\left(\times 10^{8} \mathrm{~Hz}\right)\end{array}$ & $\begin{array}{l}\text { Resonant frequency (after exposure } \\
\text { to gas }=Q)\left(\times 10^{8} \mathrm{~Hz}\right)\end{array}$ & $\begin{array}{l}\text { Shift in fre- } \\
\text { quency }=P-Q(\mathrm{~Hz})\end{array}$ \\
\hline $\mathrm{PIB} / \mathrm{LiNbO}_{3}$ & 8.490252479075134 & 8.490250779585823 & $\begin{array}{l}\text { Displace- } \\
\text { ment } \\
(\mathrm{nm})\end{array}$ \\
$\mathrm{PIB} / \mathrm{Si}_{3} \mathrm{~N}_{4} / \mathrm{LiNbO}_{3}$ & 7.986282280148824 & 7.986277816559383 & 170 \\
\hline
\end{tabular}




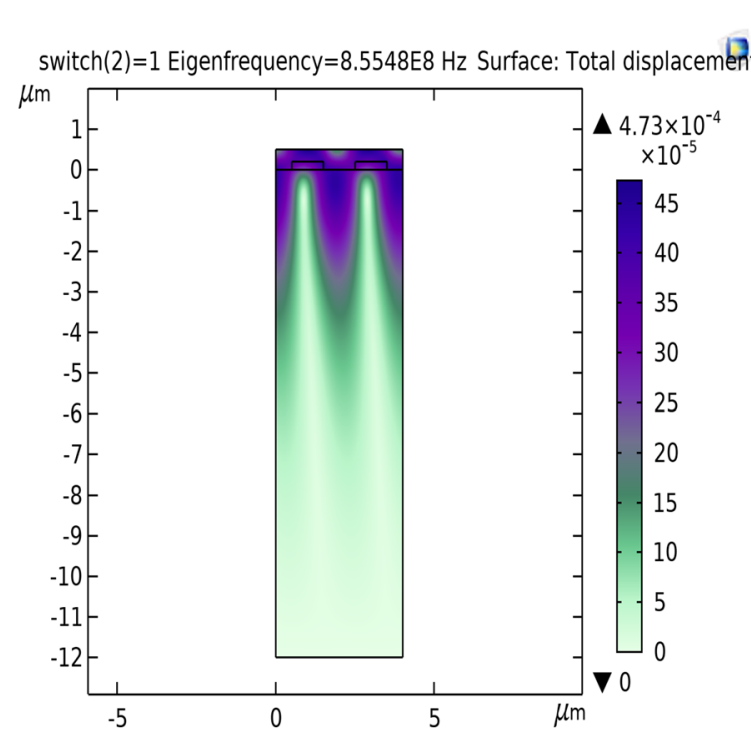

(a)

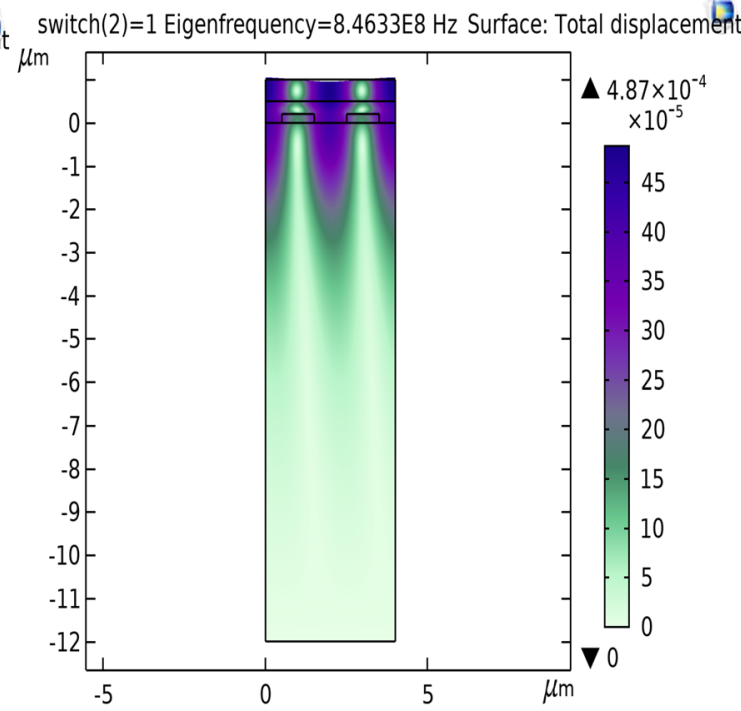

(b)

Fig. 4 Resonance SAW plot for displacement distribution for a single-layer, $\mathbf{b}$ multi-layer device configuration during exposure of DCM gas

switch(2)=1 Eigenfrequency $=8.5548 \mathrm{E} 8 \mathrm{~Hz}$ Surface: Electric potentidt $\mathrm{T} V \quad$ switch $(1)=0$ Eigenfrequency $=8.4634 \mathrm{E} 8 \mathrm{~Hz}$ Surface: Electric potentialt $\mathrm{H} v$

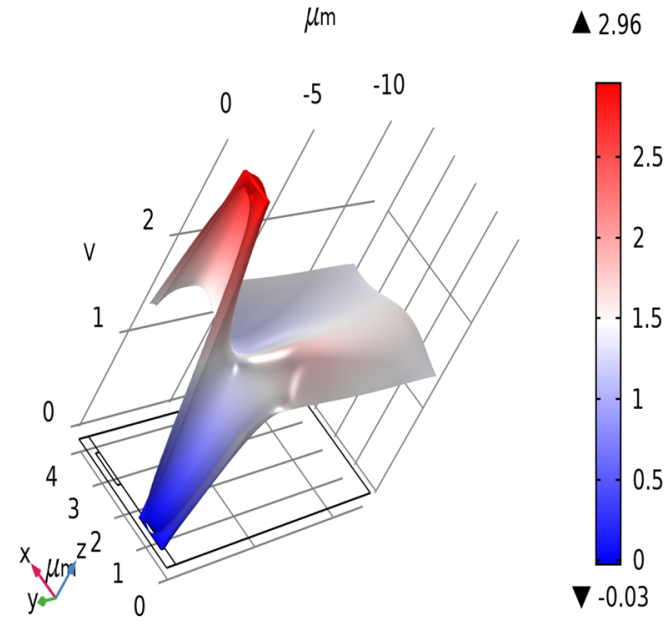

(a)

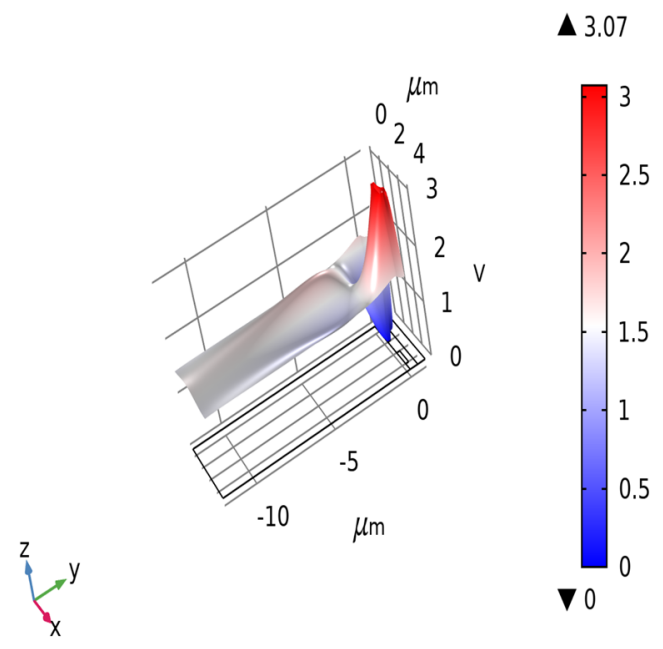

(b)

Fig. 5 Potential distribution curve for $\mathbf{a} \mathrm{PIB} / \mathrm{LiNbO}_{3}$ and $\mathbf{b} \mathrm{PIB} / \mathrm{Si}_{3} \mathrm{~N}_{4} / \mathrm{LiNbO}_{3}$ on exposing DCM gas

\section{Sensitivity Measurement}

\section{Response of Frequency Shift with Spacer Thickness}

Figure 6 shows the change in frequency shift with change of spacer thickness of single-layer structural model. The graph represents that a large recovery time is observed in case of single layer of $\mathrm{PIB} / \mathrm{LiNbO}_{3}$ sensor.
From Fig. 7, it is observed that the frequency shift of the device is very sensitive to the thickness of the additional spacer layer of the device. The frequency shift dies down after applying spacer thickness above $600 \mathrm{~nm}$. This is due to the fact that as the thickness of spacer layer from the substrate increases, the wave velocity is found to be reduced [23-25]. From Eq. (1), it can be concluded that frequency shift is also reduced. It is observed that $\mathrm{PIB} / \mathrm{Si}_{3} \mathrm{~N}_{4} / \mathrm{LiNbO}_{3}$ 
Fig. 6 Frequency shift curve with different spacer thickness for $\mathrm{PIB} / \mathrm{LiNbO}_{3}$

Fig. 7 Frequency shift curve with different spacer thickness for $\mathrm{PIB} / \mathrm{Si}_{3} \mathrm{~N}_{4} / \mathrm{LiNbO}_{3}$

Fig. 8 Frequency shift curve at different temperature ranges (for multi-layer)
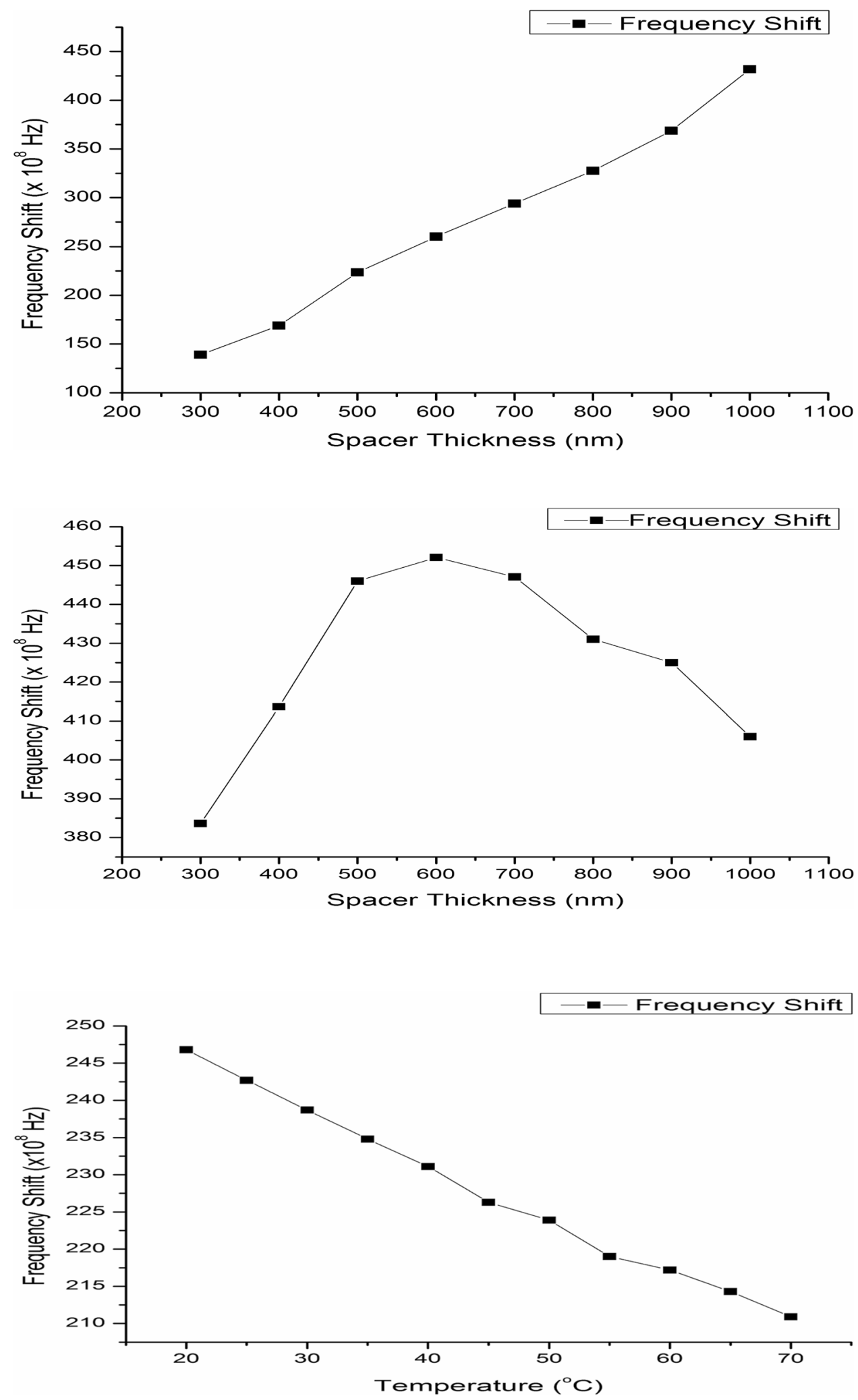
Fig. 9 Frequency shift curve at different pressure range (for multi-layer)

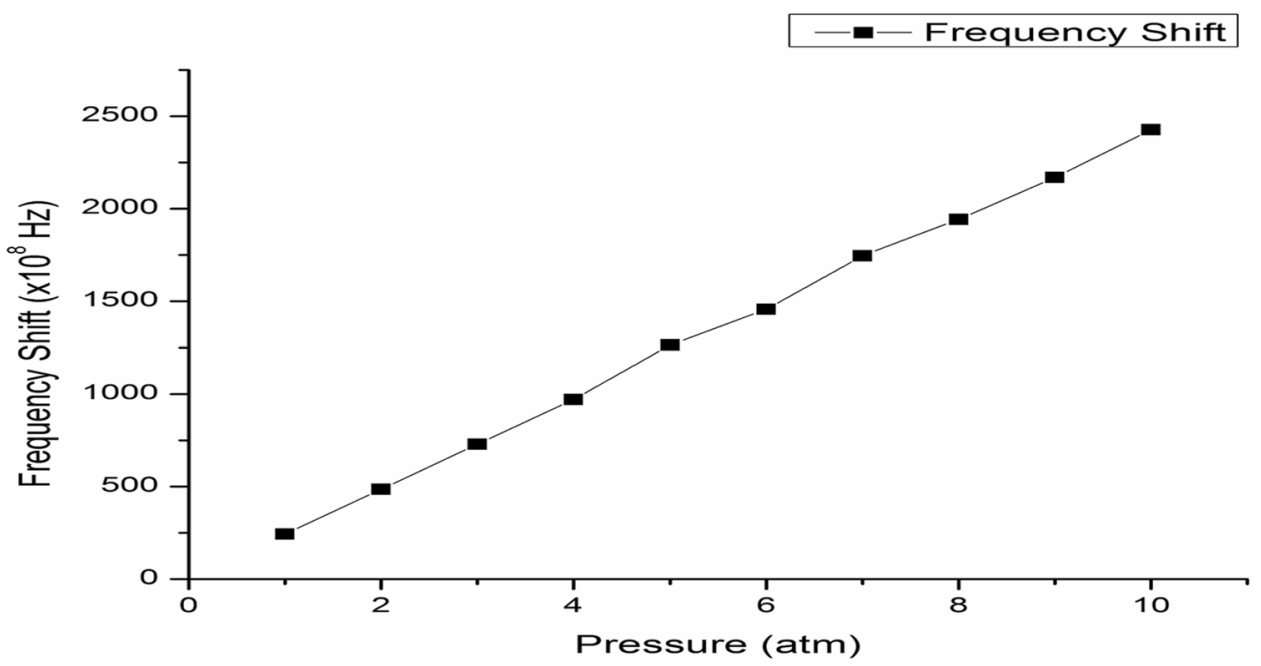

design model for DCM gas detection is more sensitive than $\mathrm{PIB} / \mathrm{LiNbO}_{3}$ (single-layer) model when the spacer thickness is below $600 \mathrm{~nm}$.

\section{Response of Frequency Shift with Temperature}

Figure 8 shows the effect of temperature on the frequency shift of multi-layer sensing film $\left(\mathrm{PIB} / \mathrm{Si}_{3} \mathrm{~N}_{4} / \mathrm{LiNbO}_{3}\right)$. With the increase in temperature above the ambient, the molecules of DCM gas evaporated and lose their contact with the sensing surface. As a result, a lesser amount of gas molecules interacts and is absorbed on the surface, which causes decrease in frequency shift in saw gas sensor. Thus, it is observed from Fig. 8 that the frequency shift is also highly sensitive to ambient temperature of multi-layer.

\section{Response of Frequency Shift with Pressure}

Figure 9 shows the relation between frequency shift and pressure of multi-layer gas sensor. Here, the effects of pressure on $\mathrm{PIB} / \mathrm{Si}_{3} \mathrm{~N}_{4} / \mathrm{LiNbO}_{3}$ are studied. When the pressure rises, the gas molecule concentration on the surface of multi-layer SAW sensor increases. The more-concentrated gas molecules cause an increase in significant modification in the surface of sensor. As pressure is increased, then more number of gas molecules are compacted in smaller region. With increase of pressure, the frequency shift has been found to increase (as shown in Fig. 9).

\section{Conclusions}

In this work, a single and multi-layer SAW-based sensors are designed and analyzed by COMSOL multiphysics. The designed sensor has been proposed for detection of DCM gas generated in gas pathway devices located in hospitals. By detecting DCM gas in proposed fashion, the life of COVID19-infected patient can be saved from other infections. The sensitivity of sensors is also investigated by analyzing its resonant frequency and displacement. By simulation results, it is analyzed and found that:

$\mathrm{PIB} / \mathrm{Si}_{3} \mathrm{~N}_{4} / \mathrm{LiNbO}_{3}$ (multi-layer) sensor exhibits higher sensitivity to the dichloromethane gas as compared to PIB/ $\mathrm{LiNbO}_{3}$ (single layer) at $100 \mathrm{ppm}$ gas concentration. Multilayer designed structure has shown a more frequency shift of $446.6 \mathrm{~Hz}$, whereas single-layer SAW sensor shows $170 \mathrm{~Hz}$ shift in frequency. The effects of spacer thickness, pressure, and electrical potential on the sensitivity are also analyzed. The simulation results show that the higher sensitivity is observed as the spacer layer thickness becomes thinner than $600 \mathrm{~nm}$. The response of the multi-layer SAW sensor is found to be considerably improved with the increase in pressure. The various volatile gases present in medical devices and environment can be detected using the designed and fabricated cost-effective multi-layer SAW-based.

Acknowledgements We thank all medical staffs who helped us in providing essential services during the COVID-19 crisis.

\section{References}

1. Aichner Verena S (2018) How to sample and to analyze VOCs of respiratory medical devices according to the new ISO 18562-3. Pharm Ind 80(10):1423-1427

2. Gupta A, Kumar P, Pandey S (2017) Analysis of multilayered SAW based gas sensor. International conference on trends in electronics and informatics (ICEI). IEEE, New York, pp 239-242

3. Malik AF, Jeoti V, Fawzy M, Iqbal A, Aslam Z, Pandian MS, Marigo E (2016) Estimation of SAW velocity and coupling coefficient in multilayered piezo-substrates $\mathrm{AlN} / \mathrm{SiO}_{2} / \mathrm{Si}$. 6th international conference on intelligent and advanced systems (ICIAS). IEEE, New York, pp 1-5 
4. Chen HH (2005) Application of Taguchi robust design method to SAW mass sensing device. IEEE Trans Ultrason Ferroelectr Freq Control 52(12):2403-2410

5. Ahmadi S, Hassani F, Korman C, Rahaman M, Zaghloul M (2004) Characterization of multi- and single-layer structure SAW sensor [gas sensor]. SENSORS. IEEE, New York, pp 1129-1132

6. Mohanan A, Islam M, Ali S, Parthiban R, Ramakrishnan N (2013) Investigation into mass loading sensitivity of sezawa wave modebased surface acoustic wave sensors. Sensors 13(2):2164-2175

7. Fechete A, Ippolito S, Wlodarski W, Kalantar-Zadeh K, Holland A, Wisistsora-at A (2005) Layered $\mathrm{InO}_{\mathrm{x}} / \mathrm{Si}_{3} \mathrm{~N}_{4} / 36 \mathrm{YX} \mathrm{LiTaO}$ surface acoustic wave based hydrogen sensor. East West J Math 32:465-470

8. Johnson S, Shanmuganantham T (2014) Design and analysis of SAW based MEMS gas sensor for the detection of volatile organic gases. Carbon 119(5):0-041316

9. Kumar M, Kumar D, Gupta AK (2015) Fe-doped $\mathrm{TiO}_{2}$ thin films for CO gas sensing. J Electron Mater 44(1):152-157

10. Niyat FY, Abadi MS (2018) COMSOL-based modeling and simulation of $\mathrm{SnO}_{2} / \mathrm{rGO}$ gas sensor for detection of $\mathrm{NO}_{2}$. Sci Rep $8(1): 2149$

11. Lerch R (1990) Simulation of piezoelectric devices by two-and three-dimensional finite elements. IEEE Trans Ultrason Ferroelectr Freq Control 37(3):233-247

12. Gaur AM, Joshi R, Kumar M (2011) Deposition of doped $\mathrm{TiO}_{2}$ thin film by sol gel technique and its characterization: a review. In: Proceedings of the world congress on engineering, London, U.K., pp 6-8

13. Kumar M, Gupta AK, Kumar D (2016) Mg-doped $\mathrm{TiO}_{2}$ thin films deposited by low cost technique for $\mathrm{CO}$ gas monitoring. Ceram Int 42(1):405-410

14. Kalantar-Zadeh K, Powell DA, Wlodarski W, Ippolito S, Galatsis K (2003) Comparison of layered based SAW sensors. Sens Actuators B Chem 91(1-3):303-308

15. Ippolito SJ, Kalantar-Zadeh K, Powell DA, Wlodarski WA (2002) Finite element approach for 3-dimensional simulation of layered acoustic wave transducers. In: Conference on optoelectronic and microelectronic materials and devices. COMMAD 2002. Proceedings (Cat. No. 02EX601). IEEE, New York, pp 541-544

16. Hasanuddin NH, Wahid MHA, Shahimin MM, Hambali NA, Yusof NR, Nazir NS, Khairuddin NZ, Azidin MAM (2016) Metal oxide based surface acoustic wave sensors for fruits maturity detection. 3rd international conference on electronic design (ICED). IEEE, New York, pp 52-55

17. Mishra D, Singh A (2015) Sensitivity of a surface acoustic wave based gas sensor: design and simulation. International conference on soft computing techniques and implementations (ICSCTI). IEEE, New York, pp 1-5

18. Kutiš V, Gálik G, Královič V, Rýger I, Mojto E, Lalinský T (2012) Modelling and simulation of SAW sensor using FEM. Procedia Eng 48:332-337

19. Gowini EL, Mohamed M, Moussa WA (2010) Finite element model of a MEMS-based surface acoustic wave hydrogen sensor. Sensors 10:1232-1250

20. Voinova MV (2009) On mass loading and dissipation measured with acoustic wave sensors: a review. J Sens 2009:943125. https ://doi.org/10.1155/2009/943125

21. Nazemi H, Joseph A, Park J, Emadi A (2019) Advanced micro-and nano-gas sensor technology: a review. Sensors 19(6):1285

22. Ruther P, Colelli K, Frerichs HP, Paul O (2003) Surface conductivity of a CMOS silicon nitride layer. SENSORS 2:920-925

23. Zheng P, Greve DW, Oppenheim IJ (2009) Multiphysics simulation of the effect of sensing and spacer layers on SAW velocity. In: COMSOL conference, Boston, pp 1-7

24. Francis LA, Friedt JM, Bartic C, Campitelli A (2004) An SU-8 liquid cell for surface acoustic wave biosensors. In: MEMS, MOEMS, and micromachining. Proceedings of the SPIE photonics, vol 5455. Europe, pp 353-363

25. Ju BF, Bai X, Chen J (2012) Simultaneous measurement of local longitudinal and transverse wave velocities, attenuation, density, and thickness of films by using point-focus ultrasonic spectroscopy. J Appl Phys 112(8):084910

Publisher's Note Springer Nature remains neutral with regard to jurisdictional claims in published maps and institutional affiliations. 